\title{
Yield performance of Oyster mushroom (Pleurotus ostreatus) on various crop residues as substrate
}

\author{
Samita Paudel $\mathbf{l}^{\dagger, 2}$ \\ Deependra Dhakal ${ }^{\dagger, 1, *}$
}

2019-08-21

\begin{abstract}
Substrate type is an important factor determining growth and yield of oyster mushroom. Five different substrates namely rice straw, maize husks, banana leaves, fingermillet husk and mixture of rice straw \& black gram pod shell (1:1) were evaluated for the yield and related attributes of Pleurotus ostreatus. Standard cultivation practice was followed with steam sterilization and spawning was done on $575 \mathrm{~g}$ of substrate in individual poly-bag. The data of three flushes were recorded. Our results revealed that full spawn run completed earlier (18.57 days) in fingermillet husk as compared to any other tested substrates. The highest total quantity yield was obtained in fingermillet husk $(1024.57 \mathrm{~g} / \mathrm{bag})$ and rice straw $(956.14 \mathrm{~g} / \mathrm{bag})$ with corresponding biological efficiency $178.19 \%$ and $166.29 \%$ respectively which were significantly higher than all other treatments. The cropping duration was significantly higher in maize husks and banana leaves as compared to rest of three treatments viz. fingermillet husk, rice straw and mixture of rice straw and black gram pod shell (1:1). These three treatments were not statistically different for cropping duration with each other. Considering the biological efficiency and earliness of crop the performance of fingermillet husk, followed by rice straw was found to be better.
\end{abstract}

Keywords - Agricultural byproducts; Biological efficiency; Cropping duration; Pleurotus ostreatus 


\section{Contents}

1 Introduction $\quad 3$

2 Materials and Method $\quad 4$

2.1 Experimental site and treatment details $\ldots \ldots \ldots \ldots \ldots \ldots$

2.2 Substrate preparation and growth condition $\ldots \ldots \ldots \ldots \ldots \ldots$

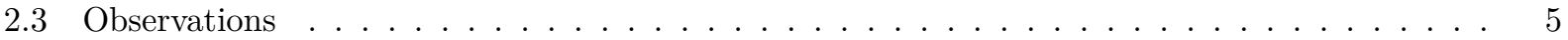

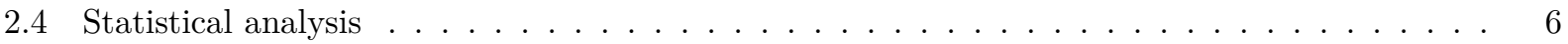

$\begin{array}{llr}3 & \text { Results and Discussion } & 7\end{array}$

3.1 Days taken for full spawn $\operatorname{run} \ldots \ldots \ldots \ldots \ldots \ldots \ldots \ldots$

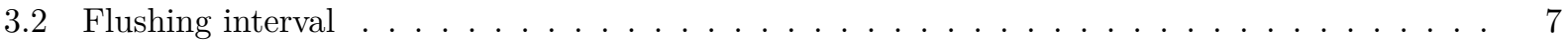

3.3 Physical attributes $($ Pileus diameter and stipe length $) \ldots \ldots \ldots \ldots$

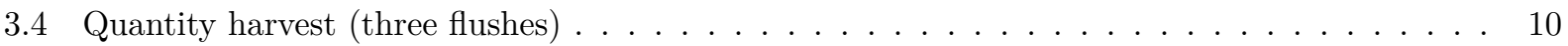

4 Conclusion $\quad 12$

$\begin{array}{ll}\text { References } & 13\end{array}$

$\dagger$ These authors contributed equally to this work.

${ }^{1}$ Agriculture and Forestry University, Chitwan, Nepal

${ }^{2}$ Institute of Agriculture and Animal Science, Tribhuwan University, Kathmandu, Nepal

* Correspondence: Deependra Dhakal <ddhakal.rookie@gmail.com> 


\section{Introduction}

Oyster mushroom (Pleurotus species) is an edible, saprophytic and lignocellulolytic type of fungus 2 belonging to the class Agaricomycetes, order Agaricales and family Pleurotaceae. It is the second widely 3 cultivated mushroom following the Agaricus bisporus in the world (Sachez 2010). There are over 70 species ${ }_{4}$ of oyster mushroom been discovered (Kong 2004) and still there are lots to explore. Pleurotus ostreatus is 5 the most popular species of oyster mushroom found in Nepal. The Latin word 'Pleurotus' means beside the 6 ear and 'ostreatus' means oyster shaped (Cohen, Persky, and Hadar 2002) and in Nepal it is often called 7 "Kanya chayu" due to the ear like appearance. Pleurotus species can efficiently degrade agricultural 8 byproducts and can grow on wide range of agricultural wastes. A substrate is any material that serves as a 9 medium of growth for a living thing in which enzymes can act upon and break it to release nutrients for 10 the growing organism. There are a range of wastes that can be used for oyster mushroom cultivation, but ${ }_{11}$ it depends on the basis of availability of the substrate and its cost.

The availability of good substrate is an important requirement for the better growth and higher yield of ${ }_{13}$ mushroom. An ideal substrate should contain adequate amount of nitrogen and carbohydrates for rapid ${ }_{14}$ mushroom growth (Khare et al. 2010). Total Carbon (C), total Nitrogen (N), Carbon/Nitrogen ratio 15 $(\mathrm{C} / \mathrm{N})$ are important factors that determines the mycelium colonized and development of fruiting bodies in $\quad 16$ oyster mushroom. Hong, Lee, and Choi (1981) have shown that in both Agaricus bitorquis and Pleurotus ${ }_{17}$ ostreatus the yield of mycelium decreases under lower or higher $\mathrm{C} / \mathrm{N}$ ratio. Pleurotus fungi mobilizes the ${ }_{18}$ carbohydrate composed in rice straw mainly through cellulose and hemicellulose degradation (Fazaeli, $\quad 19$ Azizi, and Amile 2006). Rice straw is a popular substrate for Pleurotus cultivation in Asia, mainly favored 20 for its composition of slow degrading carbohydrates. Rice straw has the chemical composition of (in ${ }^{21}$ percentage dry mass basis) $0.96 \%$ N, $73.01 \%$ NDF, $41.59 \%$ ADF, $31.42 \%$ Hemicellulose, $33.35 \%$ Cellulose ${ }_{22}^{22}$ and $4.84 \%$ Acid detergent lignin when sampled over different stages of growth, amounting to a generalized ${ }_{23}^{23}$ carbon(lignocellulosic)-nitrogen ratio of $72 \%$ (Sarnklong et al. 2010). Similarly corn cob contains $47 \%$ cellulose, $25 \%$ lignin, total Carbon $47 \%$, Nitrogen $0.48 \%$ and C/N ratio of $97: 1$ that can be used as ${ }_{25}^{25}$ substrate for Pleurotus cultivation (Wha Choi 2004). Amongst various cereal straws, paddy straw was ${ }_{26}^{26}$ 
reported to be the best substrate for the cultivation of oyster mushroom (Khanna and Garcha 1982). The ${ }^{27}$ leaves and pseudostems of banana contain high levels of lignocellulose (Reddy 2001). These lignocellulose ${ }^{28}$ materials are efficient substrates for white-rot fungi, which produce lignolytic and cellulolytic enzymes ${ }^{29}$ (Pointing 2001). Legume straws are rich in Nitrogen content and are suitable as Pleurotus substrates 30 (Poppe 1995). However, selection of right substrate to achieve high yield of oyster mushroom can be a challenge as there seems to be a wide range of agricultural crop residues available in which the oyster 32 mushroom can be grown. The objective of this study was therefore to determine the effectiveness of ${ }_{33}$ different agricultural wastes (i.e. rice straw, maize husks, banana leaves, finger millet husk and black gram 34 pod shell) on the yield performance and biological efficiency of Pleurotus ostreatus in the subtropical condition of midhills of Nepal.

\section{Materials and Method}

\subsection{Experimental site and treatment details}

The research was conducted at Institute of Agriculture and Animal Sciences, Lamjung, from and black gram pod shell (1:1)) and seven replications per treatment.

\subsection{Substrate preparation and growth condition}

The substrates were chopped to about 3-5 $\mathrm{cm}$ in length and soaked overnight in the tank filled with water. ${ }_{44}^{4}$ Substrates were steam sterilized for at least 15-20 minutes in a metallic drum while maintaining 45 temperature at $90^{\circ} \mathrm{C}$. Then, the substrates were spread over sterilized clean plastic sheet for air cooling $\quad{ }_{46}$ below $25^{\circ} \mathrm{C}$. Transparent poly-bags were taken for filling of substrate in clean and sterile condition. The ${ }_{47}$ moisture content of the substrates while filling was around $60 \%$. Substrates were filled in each poly-bags on ${ }_{48}$ 
dry weight basis: 575 g per poly-bag. Spawning, using single generation wheat grain spawn, was done at ${ }^{49}$ the rate of $10 \%$ on dry weight basis. Three layers of spawning was done, one at bottom, another at the 50 mid-section and lastly at top, starting from the bottom layer. After spawning, the bags were tightly closed ${ }_{51}$ on its open end with a rope. It was ensured that layers of spawn were observable from outside the bag. ${ }_{52}$ The bags after spawning were weighed and their respective weights recorded as initial weights. The bags ${ }_{53}$ were then perforated in 8-10 numbers with sterilized needle to permit air circulation.

The bags were moved to a production room after spawning and were hung randomly. The room was ${ }_{55}$ maintained at completely dark state using black poly-ethylene sheets. Temperature of the room was ${ }_{56}$ around $17-20^{\circ} \mathrm{C}$ and relative humidity around $90 \%$. Artificial lighting was not provisioned for the first 15 days of spawn run. After the proper development of white mycelium, the polythene covers were removed. ${ }_{58}$ At the end of the spawn run, for pinning, dim light along with sufficient fresh air was facilitated in the room through ventilation. An additional implication of this conditioning is that $\mathrm{CO}_{2}$ concentration was ${ }_{60}$ lowered. The temperature and relative humidity was maintained by sprinkling water twice a day on the ${ }^{61}$ ball of mushroom and and mushroom shed floor. The insecticide Nuvan (Dichlorovos $76 \%$ ) was sprayed in ${ }^{62}$ the substrate to avoid appearance of insects. Preventive insecticidal application was only done either since ${ }_{63}$ a week prior to pin head appearance or after harvest of the crop. The harvesting of mushroom was done ${ }^{64}$ when the cap began to fold. The picking was done by twisting the mushroom gently and pulling out, leaving any stub. Cropping was done up to three flushes.

\subsection{Observations}

Observations were taken on growth attributes like days taken for full spawn run (days), Days taken for ${ }^{68}$ first, second harvest and final harvest (latter also referred occassionally to as cropping duration) (days) and ${ }^{69}$ Quantity harvested in all three flushes (g). Beyond third flush, maintainance of mushroom production unit 70 generally seemed uneconomical. Hence, no further observations were recorded.

Fruiting bodies were weighed and measured for their physical attributes (Pileus diameter and Stipe 72 length) after each harvest. The biological efficiency of mushroom (per gram of substrate on dry wt. basis) 73 
was calculated by using the following formula:

B.E. $\%=\frac{\text { Fresh weight of total quantity harvested from each bag }}{\text { Dry weight of substrate on each bag }} \times 100$

\subsection{Statistical analysis}

Each harvest of fruiting bodies was screened for appropriate number of samples in recording data. Sample 76 observations were checkd for outliers and only representative fruiting bodies taken as samples. Regression 77 models with both fixed and random terms were specified for responses where applicable. Analysis of ${ }_{78}$ variance was performed to determine the significance of experimental factors. Linear model of the following 79 form was used to analyse quantity harvested, as being determined by the growth substrate, harvest stage: $\quad 80$

$$
Y_{i}=X_{i} \times \beta+Z_{i} \times b_{i}+\epsilon_{i}
$$

Where,

$\boldsymbol{Y}_{\boldsymbol{i}}$ is a vector of dependent variable,

$\boldsymbol{X}_{\boldsymbol{i}}$ is a column vector of independent variables,

$Z_{\boldsymbol{i}}$ is a column vector of random effect variables,

$b_{1}, \ldots, b_{N} ; \epsilon_{1}, \ldots, \epsilon_{N}$ independent.

From the initial model testing, it was evident that linear mixed model with independent errors were not $\quad 88$ quite suitable structure for treatment factors. In fact, various levels of treatments have heterogeneous ${ }_{89}$ variance. We accounted for this uneven variance by extending the random intercept model from 
have a different variance than treatment 2 , treatment 2 has the one different from treatment 3 , and so on. 92

Whenever treatment factor had significant effects, treatment means were compared for their difference 93 using multiple range test at 5\% level of significance. Group differences were confirmed based on adjusted 94 p-values. Model summaries and parameters were tabulated for all response variables and fits described. ${ }_{95}$ Correlation analysis was done to check if any causal effects are possible for yield quantities due to growth 96 or physical attributes.

\section{Results and Discussion}

\subsection{Days taken for full spawn run}

The number of days taken for full spawn run ranged from 18.57 days to 23.29 days on different substrates 102 (Table 1). Significantly lowest number of days for full spawn run was recorded on fingermillet husk (18.57 ${ }_{103}$ days) and the mixture of rice straw and black gram pod shell (1:1) (19.0 days). Banana leaves (23.29 days) 104 and rice straw (22.14 days) took the highest number of days for completion of full spawn run followed by 105 maize husks (20.86 days). Our results were almost similar to the findings of Shah, Ashraf, and Ishtiaq 106 (2004) who reported that the spawn running took in 16-25 days after inoculation. This variation in number ${ }^{107}$ of days taken for full spawn run in different substrates could be due to the variations in chemical composition and Carbon-Nitrogen ratio (C: N) of the substrates used (Bhatti et al. 2007).

\subsection{Flushing interval}

Observations recorded for flushing intervals (i.e days taken from spawining to first harvest, first harvest to $\quad{ }_{111}$ second harvest, and second harvest to third harvest) of oyster mushroom (Table 2) shows the comparison ${ }_{112}$ of marginal means between tested substrates. 
The days taken for first harvest of mushroom were significantly affected by substrates used. The average numbers of days taken for first harvest were between 38-46 days. The earliest harvest was noted on ${ }_{115}$ fingermillet husk (38 days) and mixture of rice straw: black gram pod (1:1) (38.71 days) followed by maize 116 husks (40.14 days) and rice straw (40.86 days). Banana leaves took significantly the highest number of days ${ }_{117}$ (46.86 days) for first harvest. Contrary to our study Quimio et al. (1990) reported that good harvest of $P$. 118 ostreatus was obtained 3-4 weeks after spawn inoculation.

The cropping duration was significantly longest on maize husks (96.86 days) and banana leaves (94.43 127 days). Whereas the shortest cropping duration was recorded in fingermillet husk (69.57 days), rice straw ${ }_{128}$ (72.43 days) and mixture of rice straw and black gram pod shell (1:1) (71 days) which were not significantly different with each other. The cropping duration in our study ranged from 69 days to 96 days 130 which is similar to findings of Khanna and Garcha (1982) that it may take up-to 104 days to harvest yield 131 from oyster mushroom grown on paddy straw. The variation in cropping period among different substrates ${ }_{132}$ could emanate from variations in the time elapsed in formation of pinheads, maturation of fruiting bodies, 133 interval between flushes, number of flushes and yield, which in turn is affected by the nature of the substrates (Chang, Lau, and Cho 1981).

\subsection{Physical attributes (Pileus diameter and stipe length)}




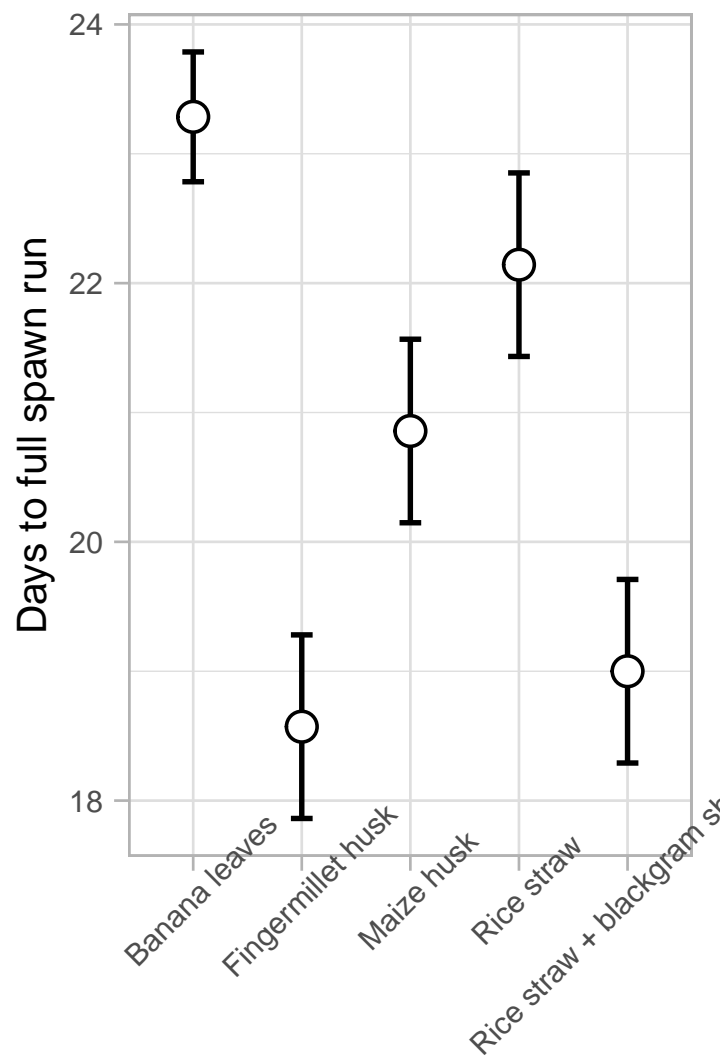

Substrate type

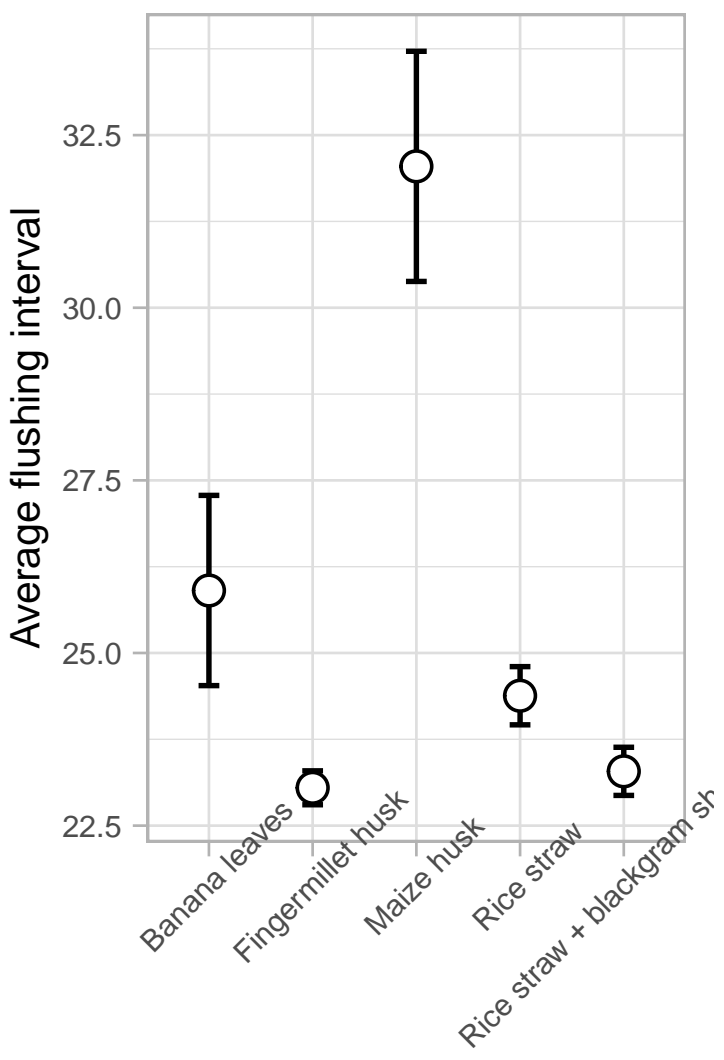

Substrate type

Figure 1. (a) Mean differences in days to full spawn run starting from the first day of spawning from use of different growth substrates (b)

Effect of substrate used on flushing interval 

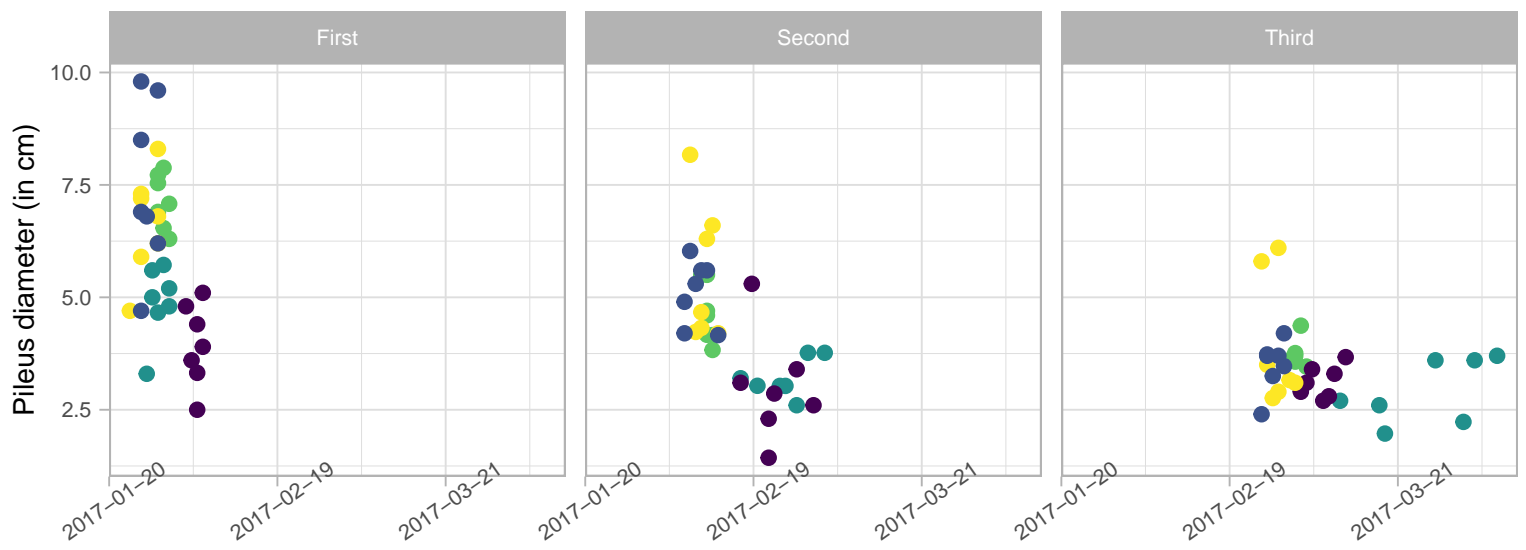

Date

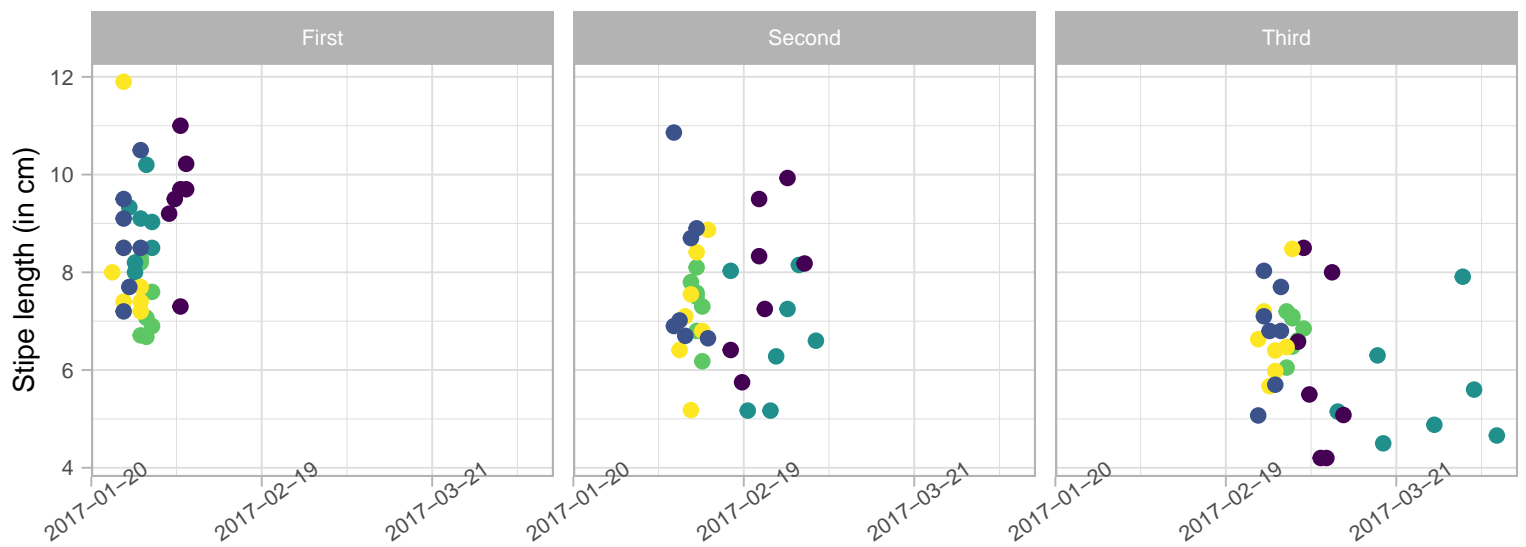

Date

Treatment - Banana leaves - Fingermillet husk - Maize husk $\bullet$ Rice straw Rice straw + blackgram shells (1:1)

\subsection{Quantity harvest (three flushes)}

The quantity harvest varied significantly on the different substrates in all of the three flushes (Table 2). In ${ }^{141}$ the first flush, highest quantity harvest $(571.43 \mathrm{~g})$ was obtained on fingermillet husk followed by rice straw ${ }_{142}$ (453.57 g) and mixture of rice straw and black gram pod shell (1:1) (426.86 g). The lowest yield was obtained on banana leaves (256.71 g) and maize husks (258.86 g).

In the second flush, rice straw (369 g) and fingermillet husk (328.29 g) produced the highest yield followed by the mixture of rice straw and black gram pod shell (1:1) (241.43 g). In the same flush, the lowest yield was obtained on maize husks (151.43 g) and banana leaves (218.71 g). 
In the third flush highest yield was obtained on rice straw (133.57 g), mixture of rice straw and black ${ }_{148}$ gram pod shell (1:1) (127.71 g) and fingermillet husk (124.86 g) respectively. In the same flush, the lowest ${ }^{149}$ yield was recorded on maize husks $(45.27 \mathrm{~g})$ and banana leaves $(53.43 \mathrm{~g})$.

The total quantity harvest result showed the significant difference between the tested substrates ??.

Table 1. Summary of treatment effects and model parameters

\begin{tabular}{llll}
\hline & Days to full spawn run (days) & Flushing interval (days) & Quantity harvested (g) \\
\hline Intercept & $23.29(0.5)^{* * *}$ & $41.09(1.4)^{* * *}$ & $130.46(60.48)^{*}$ \\
Harvestsecond days & & $-25.05(0.44)^{* * *}$ & \\
Harvestthird days & & $-20.51(0.44)^{* * *}$ & $15.65(5.5)^{* *}$ \\
Pileus diameter & $-4.71(0.71)^{* * *}$ & & $127.03(26.41)^{* * *}$ \\
Fingermillet husk & $-2.43(0.71)^{* *}$ & $-2.86(1.4)^{*}$ & $-32.56(19.67)$ \\
Maize husk & $-1.14(0.71)$ & $6.14(2.16)^{* *}$ & $110.49(20.99)^{* * *}$ \\
Rice straw & $-4.29(0.71)^{* * *}$ & $-1.52(1.44)$ & $51.23(18.55)^{* *}$ \\
Rice straw + blackgram shells $1: 1$ & $-2.62(1.42)$ & 1207.115 \\
\hline Akaike IC & 125.754 & 531.817 & 1238.962 \\
Bayesian IC & 135.086 & 566.318 & 105 \\
Observations & 35 & 105 & \\
\hline
\end{tabular}


Quantity harvested in our study could otherwise be stated in terms of Biological efficiency of the under lower or higher $\mathrm{C} / \mathrm{N}$ ratio (Warcup 1951).

Table 2. Mean comparison of treatment substrate for effects in economic

\begin{tabular}{llll} 
& \multicolumn{2}{c}{ traits } & \\
Treatment Description & Full Spawn & Flushing & Quantity \\
& Run & Interval & Harvested \\
\hline Fingermillet husk & $18.571(1)$ & $23.048(1)$ & $329.197(3)$ \\
Rice straw + blackgram shells (1:1) & $19.000(12)$ & $23.286(1)$ & $253.402(2)$ \\
Maize husk & $20.857(23)$ & $32.048(2)$ & $169.612(1)$ \\
Rice straw & $22.143(34)$ & $24.381(1)$ & $312.661(3)$ \\
Banana leaves & $23.286(4)$ & $25.905(1)$ & $202.172(12)$ \\
\hline
\end{tabular}

a Same numerals inside the brackets signify absence of difference in treatment means

\section{Conclusion}

From the present study it is confirmed that oyster mushroom (Pleurotus ostreatus) can be cultivated on ${ }_{173}$ rice straw, maize husks, banana leaves, fingermillet husk and mixture of rice straw \& black gram pod (1:1) $\quad{ }_{174}$ with varying growth performances. Fingermillet husk and rice straw were identified as the most suitable 175 substrates for oyster mushroom cultivation. Fingermillet husk and rice straw followed by mixture of rice 176 
straw and black gram pod shell (1:1) produced a significantly higher yield and biological efficiency in

\section{References}

Bhatti, MI, MM Jiskani, KH Wagan, MA Pathan, and MR Magsi. 2007. "Growth, Development and Yield ${ }_{187}$ of Oyster Mushroom, Pleurotus Ostreatus (Jacq. Ex. Fr.) Kummer as Affected by Different Spawn Rates." ${ }^{188}$ Pak. J. Bot 39 (7): 2685-92. 
Khanna, P, and HS Garcha. 1982. "Utilization of Paddy Straw for Cultivation of Pleurotus Species." Mushroom Newsl. Trop 2 (1): 5-9.

Khare, KB, JM Mutuku, OS Achwania, and DO Otaye. 2010. "Production of Two Oyster Mushrooms, ${ }_{202}$ Pleurotus Sajor-Caju and P. Florida on Supplemented and Un-Supplemented Substrates." Journal Article. 203 International Journal of Agriculture and Applied Sciences 6: 4-11. 204

Kong, Won-Sik. 2004. "Descriptions of Commercially Important Pleurotus Species." Journal Article. 205 Oyster Mushroom Cultivation. Part II. Oyster Mushrooms. Seoul: Heineart Incorporation, 54-61. 206

Núñez, J Pardo, and C Garca Mendoza. 2002. "Submerged Fermentation of Lignocellulosic Wastes 207 Under Moderate Temperature Conditions for Oyster Mushroom Growing Substrates." Mushroom Biology 208 and Mushroom Products 5: 545-49. 209

Pointing, S. 2001. "Feasibility of Bioremediation by White-Rot Fungi." Journal Article. Applied Microbiology and Biotechnology 57 (1-2): 20-33.

Ponmurugan, P, Y Nataraja Sekhar, and TR Sreesakthi. 2007. "Effect of Various Substrates on the 212 Growth and Quality of Mushrooms." Pakistan Journal of Biological Sciences 10 (1): 171-73.

Poppe, J. 1995. "Cultivation of Edible Mushrooms on Tropical Agricultural Wastes." Journal Article. ${ }^{214}$ University of Gent, Gent.

Quimio, TH, Shu-ting Chang, Daniel Joseph Royse, and others. 1990. Technical Guidelines for ${ }^{216}$ Mushroom Growing in the Tropics. 
Different Treatments to Improve Its Feed Value for Ruminants: A Review." Asian-Australasian Journal of ${ }^{224}$

Animal Sciences 23 (5): 680-92. 225

Shah, ZA, M Ashraf, and M Ishtiaq. 2004. "Comparative Study on Cultivation and Yield Performance ${ }^{226}$ of Oyster Mushroom (Pleurotus Ostreatus) on Different Substrates (Wheat Straw, Leaves, Saw Dust)."

Pakistan Journal of Nutrition 3 (3): 158-60.

Warcup, JH. 1951. "Studies on the Growth of Basidiomycetes in Soil." Annals of Botany 15 (3): $305-18 . \quad 229$

Wha Choi, Kyung. 2004. "Shelf Cultivation of Oyster Mushroom with Emphasis on Substrate 230

Fermentation." Mushroom GrowersHandbook 1: Oyster Mushroom Cultivation MushWorld, January. 